\title{
Shank Expression Is Sufficient to Induce Functional Dendritic Spine Synapses in Aspiny Neurons
}

\author{
Gautier Roussignol, ${ }^{1}$ Fabrice Ango, ${ }^{1}$ Stefano Romorini, ${ }^{2}$ Jian Cheng Tu, ${ }^{3}$ Carlo Sala, ${ }^{2}$ Paul F. Worley, ${ }^{3}$ Joël Bockaert, ${ }^{1}$ \\ and Laurent Fagni ${ }^{1}$ \\ ${ }^{1}$ Institut de Génomique Fonctionnelle, Unité Mixte de Recherche 5203, 34000 Montpellier, France, ${ }^{2}$ Consiglio Nazionale delle Ricerche, Institute of \\ Neuroscience, University of Milan, 20129 Milan, Italy, and ${ }^{3}$ Department of Neurosciences, The Johns Hopkins University School of Medicine, Baltimore, \\ Maryland 21205
}

Shank proteins assemble glutamate receptors with their intracellular signaling apparatus and cytoskeleton at the postsynaptic density. Whether Shank plays a role in spinogenesis and synaptogenesis remained unclear. Here, we report that knock-down of Shank3/prolinerich synapse-associated protein- 2 by RNA interference reduces spine density in hippocampal neurons. Moreover, transgene expression of Shank 3 is sufficient to induce functional dendritic spines in aspiny cerebellar neurons. Transfected Shank protein recruits functional glutamate receptors, increases the number and size of synaptic contacts, and increases amplitude, frequency, and the AMPA component of miniature EPSCs, similar to what is observed during synapse developmental maturation. Mutation/deletion approaches indicate that these effects require interactions of Shank3 with the glutamate receptor complex. Consistent with this observation, chronic treatment with glutamate receptor antagonists alters maturation of the Shank3-induced spines. These results strongly suggest that Shank proteins and the associated glutamate receptors participate in a concerted manner to form spines and functional synapses.

Key words: synapse; glutamate; patch clamp; synaptogenesis; granule cell; Shank

\section{Introduction}

Principal neurons of the mammalian brain receive most of their excitatory inputs on dendritic spines (Engert and Bonhoeffer, 1999; Matus, 2000; Goldin et al., 2001; Hering and Sheng, 2001). These structures consist of a neck and bulbous head with a postsynaptic density containing glutamate receptor (GluR) complexes. It is generally assumed that spine formation begins with a long headless dynamic dendritic filopodium which then shortens, enlarges, and stabilizes during maturation (Luscher et al., 2000). Intracellular $\mathrm{Ca}^{2+}$ (Korkotian and Segal, 1999), glutamate receptors (McKinney et al., 1999), and proteins of the postsynaptic density (Garner et al., 2000; Hering and Sheng, 2001; Ehlers, 2002) contribute to this process. Nevertheless, little is known about the molecular determinants responsible for spine induction. It has been proposed that afferent innervation precedes spine formation (Fiala et al., 1998), but spines also exist on neu-

Received 0ct. 20, 2004; revised Feb. 15, 2005; accepted Feb. 15, 2005.

This work was supported by the Centre National de la Recherche Scientifique, the Institut National de la Santé et de la Recherche Médicale, Genopole Languedoc-Rousillon fundings, the European Community (LSHM-CT-2004511995, SYNSCAFF), and the National Institute on Drug Abuse. G.R. was supported by a Ministere de l'Education Nationale de Pa Recherche et de la Technologie grant, and C.S. was supported by the Giovanni Amenise-Harvard Foundation Career Development Program. We thank Dr. Jacques Neyton for providing us with NR1 and NR2B subunit CDNAs. We also thank Dr. Federica Bertaso for helpful discussion.

Correspondence should be addressed to Dr. Laurent Fagni, Institut de Génomique Fonctionnelle, Unité Mixte de Recherche 5203, 141 Rue de la Cardonille, 34000 Montpellier, France. E-mail: Ifagni@ccipe.cnrs.fr.

G. Roussignol's present address: Sanofi-Aventis, 371 Rue du Professeur Blayac, 34000 Montpellier, France.

F. Ango's present address: Cold Spring Harbor Laboratory, Cold Spring Harbor, NY 11724

D0I:10.1523/JNEUROSCI.4354-04.2005

Copyright $\odot 2005$ Society for Neuroscience $\quad$ 0270-6474/05/253560-11\$15.00/0 rons that do not receive any input, suggesting the existence of intrinsic pathways independent of axonal contact (Yuste and Bonhoeffer, 2004).

Shank proteins are the products of three genes, Shankl, Shank2, and Shank3. They are major components of the postsynaptic density (Sheng and Kim, 2000; Böckers et al., 2002; Ehlers, 2002 ) and display several protein-protein interaction domains. First, they contain a postsynaptic density-95 (PSD-95)/Discs large/zona occludens-1 (PDZ) domain that allows Shank to bind indirectly to the multiprotein NMDA and AMPA receptor (NMDAR and AMPAR) complexes via the guanylate kinaseassociated protein (GKAP) (Kim et al., 1997) but also directly to the $\mathrm{C}$ terminus of group I metabotropic glutamate receptors (mGluRs) (Tu et al., 1999). Second, they contain a ligand motif for Homer (Tu et al., 1999), a family of proteins that binds to group I metabotropic glutamate receptors, $\mathrm{IP}_{3}$ receptors, and ryanodine receptors (Xiao et al., 1998). Shank1 and Shank3 display N-terminal ankyrin repeats, which bind to spectrin (Boeckers et al., 2001), C-terminal interaction sites for cortactin (Naisbitt et al., 1999; Böckers et al., 2002), and Abp1 (Qualmann et al., 2004), all F-actin-associated proteins. Thus, Shank proteins link ionotropic and metabotropic glutamate receptor complexes together and to the cytoskeleton. Shank proteins can dimerize through PDZ-PDZ (Im et al., 2003), extreme C-terminal sterile $\alpha$ motif (SAM)-SAM (Naisbitt et al., 1999), and ankyrin repeatsSrc homology 3 (SH3) interactions (Romorini et al., 2004). The PDZ motif of Shank can also interact with p21-associated kinase interacting exchange factor $\beta$ (Park et al., 2003). Thus, Shank appears as a key postsynaptic scaffolding protein. Interestingly, 
haploinsufficiency of Shank3 in humans is associated with mild mental retardation [the so-called 22q13 deletion syndrome (Bonaglia et al., 2001; Wilson et al., 2003), a type of syndrome that is correlated with dendritic spine dysgenesis (Ramackers, 2002)].

Transfection of Shank has been shown to enlarge existing dendritic spines in cultured hippocampal neurons (Sala et al., 2001), but whether Shank proteins can also induce formation of new functional spines has not yet been elucidated. Here, we studied this issue in the aspiny cultured cerebellar granule cells (CGCs). Our results show that transgene expression of Shank is sufficient to induce de novo formation of mature spines and this effect is dependent on interaction of Shank with glutamate receptor complexes.

\section{Materials and Methods}

Culture preparation and transfection. Primary cultures of cerebellar neurons were prepared from postnatal day 5-7 mice. Neurons were dissociated and plated in 35-mm-diameter Petri dishes coated with poly-Lornithin at a density of $3-5 \times 10^{5}$ cells per dish. The culture medium consisted of DMEM-F-12 supplemented with $10 \%$ fetal calf semisynthetic serum (BioWhittaker Cambrex, Walkersville, MD), 2 mm glutamine, $100 \mu \mathrm{M}$ gentamycin, and $25 \mathrm{~mm} \mathrm{KCl}$. Neurons were transfected immediately before plating with wild-type myc-Shank3 or mutant mycShank3 cDNA expression plasmids using a previously described lipofection method (Transfast; Promega, Charbonniere, France) (Ango et al., 1999). Enhanced green fluorescent protein expression plasmid (pEGFPN1; Clontech, Cambridge, UK) was used to improve visualization of neuron morphology and as a transfection marker in electrophysiological studies. GFP and wild-type Shank3 or mutant Shank3 cDNA were cotransfected at a ratio of 1:2. We have shown previously that under such conditions, $90 \%$ of GFP-expressing cells were also transfected with the plasmid of interest (Ango et al., 1999). Expression of the transfected wild-type myc-Shank3 or Shank3 mutants was verified in CGCs by immunostaining using an anti-myc or anti-Shank antibody as described below. Hippocampal cultures were prepared from embryonic day 17 (E17) to E18 rats and grown in B27-supplemented Neurobasal medium. These cultures were cotransfected with GFP and expression plasmids using calcium phosphate precipitation as described previously (Sala et al., 2001). Experiments were performed from mature neurons [10-12 d in vitro (DIV) CGC and 18-21 DIV hippocampal neurons]. Data were collected from at least three different dishes prepared from at least three different cultures (40-50 neurons).

The COS-7 cells were cultured and transfected as described previously (Kim et al., 1996). Two days after transfection, they were washed in a PBS buffer containing protease inhibitor (Complete EDTA; F. Hoffmann-La Roche, Basel, Switzerland) and extracted in radioimmunoprecipitation assay buffer (50 mu Tris- $\mathrm{HCl}, \mathrm{pH}$ 7.6, $150 \mathrm{~mm} \mathrm{NaCl}, 1 \mathrm{~mm}$ EDTA, 1\% NP-40, 0.1\% SDS, and 0.5\% deoxycholate) for Western blotting.

Immunological analyses. Western blots were performed as described previously (Ango et al., 2000) using a rabbit polyclonal pan anti-Shank antibody (1:3000). The specificity of the antibody has been characterized previously (Tu et al., 1999). Western blot quantification was performed by measuring band intensity with the ImageJ freeware (W. S. Rasband, National Institutes of Health, Bethesda, MD; http://rsb.info.nih.gov/ij/). The data were then plotted as ratio over background intensity taken in a nonimmunoreactive region of the blot. For immunocytochemistry, cultured neurons were fixed with paraformaldehyde glucose $(4 \% ; 10-15$ min) and permeabilized with Triton X-100 $(0.05 \%)$ at room temperature or cold $\left(-20^{\circ} \mathrm{C}\right)$ methanol $\left(10 \mathrm{~min}\right.$ at $\left.-4^{\circ} \mathrm{C}\right)$. The cultures were exposed to PBS serum (20\%) for $1 \mathrm{~h}$ and then incubated with the rabbit pan anti-Shank antibody [number 3856; 1:1000 (Lim et al. 1999)] or mouse anti-myc (Sigma, St. Louis, MO) and/or anti-PDS-95 (Chemicon, Temecula, CA), anti-synaptophysin (Chemicon), anti-NR1 (Zymed, San Francisco, CA), anti-GluR1/2/3 (Zymed), anti-GABA (Abcam, Cambridge, UK), and anti-mGluR1 (Upstate Biotechnology, Lake Placid, $\mathrm{NY}$ ) antibodies, all at a dilution of 1:500, overnight at $4^{\circ} \mathrm{C}$, in a PBS serum
(1\%) solution. Neurons were then incubated in the presence of Alexa488- (green) or Alexa580- (red) conjugated anti-mouse secondary antibody (1:1000; Jackson ImmunoResearch, West Grove, PA). Cultures were mounted on an upright Axiophot Zeiss (Oberkochen, Germany) microscope for observation at $63 \times$ or $100 \times$ magnification. Images were acquired using a Hamamatsu (Bridgewater, NJ) CCD camera (16 bits; $1280 \times 1024$ pixels per image) or a Bio-Rad (Hercules, CA) MRC1024 confocal microscope and analyzed with Photoshop (Adobe Systems, San Jose, CA) software.

Immunofluorescence quantification was performed as follows. Total fluorescence of a selected area of a neuron was measured and expressed as fluorescence density arbitrary units on a linear scale of 0-256 and in nonsaturating condition of the camera, using the ImageJ software. Fluorescence density values were then averaged and expressed relative to mean fluorescence density obtained from background noise. For colocalization analysis, images were merged, sorted, and colocalized pixels were counted using the ImageJ software.

In morphological studies, filopodia were defined as thin dendritic protrusions devoid of head, whereas spines were defined as dendritic protrusions with neck and head. Examples are given in Figure $3 D$. Dendrites of transfected neurons were selected randomly, and protrusions (spines and filopodia) were traced manually. They were then sorted into filopodia and spine categories and counted per $500 \mu \mathrm{m}$ length of dendrite. This was performed, for each condition (except for conditions in which no protrusions was found; see Table 1), on 40-50 different neurons, representing 70-90 dendrites and 1300-10,500 protrusions, depending on the experimental condition. The total number of spines was expressed as density per $100 \mu \mathrm{m}$ length of dendrite, and the percentage of spines over filopodia was calculated by dividing the number of protrusions of each category by the total number of protrusions (see Table 1). The length of the neck and width of the head of each traced spine was then measured using ObjectImage (N. Vischer; http://simon.bio.uva.nl/object-image.html) or Metamorph (Universal Imaging, West Chester, PA) software. Data were expressed as mean \pm SEM, and statistical differences between groups were tested using the nonparametric Wilcoxon's test. They were considered significant at ${ }^{*} p \leq 0.05$ or ${ }^{* *} p \leq 0.01$.

Plasmids. For plasmid-based RNA inhibition of Shank3, the following complementary oligonucleotides were annealed and inserted into the HindIII/BglII sites of pSUPER vector (OligoEngine, Seattle, WA) (Brummelkamp et al., 2002): 5' -GATC CCC G GTT CTT CGC AAT GGC GGT TTC AAG AGA ACC GCC ATT GCG AAG AAC C TTTTT GG AAA-3' and 5'-AGCT TTT CC AAAAA G GTT CTT CGC AAT GGC GGT TCT CTT GAA ACC GCC ATT GCG AAG AAC CGGG-3' (corresponding to nucleotides 732-752 of rat Shank3 from the National Center for Biotechnology Information clone AF133301).

Full-length Shank3 was cloned into N-terminal myc-tagged pRK5 or $\mathrm{N}$-terminal hemagglutinin (HA)-tagged GW1 (British Biotechnology, Oxford, UK) vector with a clone taken from a library screen. We generated expression plasmids for the following Shank3 mutants: a HAShank3 plasmid (Shank3r, for Shank3 rescue) carrying three silent mutations at positions $737(\mathrm{~T} \rightarrow \mathrm{A}), 740(\mathrm{~T} \rightarrow \mathrm{A})$, and $746(\mathrm{~T} \rightarrow \mathrm{C})$; mycShank3-P1311L and myc-Shank3-F1314C point mutations (see Fig. 3A), which were made using site-directed mutagenesis (Stratagene, La Jolla, CA) on a PCR fragment; and myc-Shank3 deletion mutants (see Fig. 3A), which were made by multiple-step PCR and subcloning. All Shank3 mutants were then inserted into pRK5. All PCR fragments and all junctions of subcloned fragments were confirmed by DNA sequencing. Quantitative immunostaining analyses showed that all the Shank3 mutants displayed equivalent expression level as the full-length Shank3 in transfected CGCs. HA-tagged Shank1B (a splice variant of Shank1 deleted of the SAM domain) and Shank2 were prepared as described previously (Lim et al., 1999; Sala et al. 2001).

Electrophysiology. Cerebellar granule cells cotransfected with GFP and the plasmid of interest were selected based on their fluorescence and recorded at room temperature using the whole-cell configuration of the patch-clamp technique. The recording pipettes had resistance of 3-5 $\mathrm{M} \Omega$ 
when filled with the following medium (in mM): $140 \mathrm{CsCl}, 0.5 \mathrm{CaCl}_{2}, 20$ EGTA, 10 HEPES, 10 D-glucose, $\mathrm{pH} 7.2$ and osmolarity of $300 \mathrm{mOsm}$. The high concentration of EGTA avoided slow $\mathrm{Ca}^{2+}$-dependent desensitization of NMDARs (Medina et al., 1996). Neurons were perfused continuously with the following external medium (in $\mathrm{mM}$ ): 140 $\mathrm{NaCl}, 2 \mathrm{CaCl}_{2}, 3 \mathrm{KCl}, 10$ HEPES, 10 D-glucose, 0.01 glycine, 0.0003 tetrodotoxin, pH 7.4 and osmolarity of $330 \mathrm{mOsm}$. Bicucullin $(10 \mu \mathrm{M})$ was added when recording miniature and spontaneous EPSCs (mEPSCs and sEPSCs). Tetrodotoxin was omitted when recording sEPSCs. Currents were recorded through an Axopatch 200B amplifier (Axon Instruments, Union City, CA), filtered at $1 \mathrm{kHz}$, and continuously stored on a tape recorder. The data were then digitized at 3 $\mathrm{kHz}$ using Axotape and analyzed with Axograph software (Axon Instruments). Control neurons displayed average cell capacitance of $10 \pm 1 \mathrm{pF}$ and input resistance of $2.1 \pm 0.3$ $\mathrm{G} \Omega$. These values were not significantly modified in transfected neurons.

Agonists were applied using a fast gravity perfusion system that allowed complete exchange of the cell environment in $<50 \mathrm{~ms}$ (Fagni et al., 1995). Current-voltage relationships were obtained on agonist-mediated currents measured at their peak amplitude and plotted as a function of membrane potential.

Cell-attached recordings of single channels were performed using 2-3 $\mathrm{M} \Omega$ pipettes filled with the external medium. For recording of NMDA channels, this medium was supplemented with $100 \mu \mathrm{M}$ NMDA. For recording of single $\mathrm{Ca}^{2+}$-dependent big $\mathrm{K}^{+}(\mathrm{BK})$ channels, glycine was omitted from the pipette solution. Distribution of unitary NMDA current amplitudes was obtained using pClamp6 (Axon Instruments), and the mean amplitude was plotted as a function of membrane potential. The NMDA single-channel conductance was then calculated by fitting the current-voltage relationships between -100 and $+20 \mathrm{mV}$. The open probability $\left(P_{0}\right)$ of single BK channels was measured at $+20 \mathrm{mV}$. The membrane potential of the cell-attached patch was calculated with respect to the reversal potential of the recorded NMDA or BK channel unitary currents that were assumed to be equal to the resting potential of the neuron.

During EPSC recording, the cell was held at $-65 \mathrm{mV}$. Miniature and spontaneous EPSCs were analyzed using the Axograph software (Axon Instruments). Once a minimal sample of at least 50 events had been collected from a neuron, the average frequency and amplitude of these events were measured on the total duration of the sample. Fitting of the decay phase of currents was performed on an averaged EPSC using a simplex algorithm for least-squares exponential fitting routines. The decay time of averaged ESPCs was obtained from fitting a single or double exponential equations of the following form: $I(t)=A_{0} \exp \left(-t / \tau_{0}\right)+A_{1} \exp \left(-t / \tau_{1}\right)+$ $C$, where $A_{0}$ and $A_{1}$ are the amplitudes of the slow and fast decay components, $\tau_{0}$ and $\tau_{1}$ are their respective decay time constants, and $C$ is a constant.
A

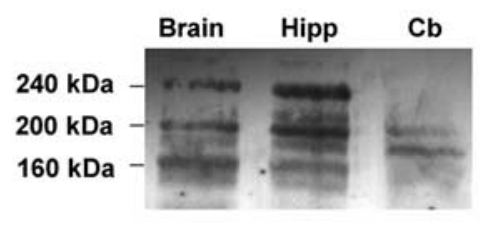

C

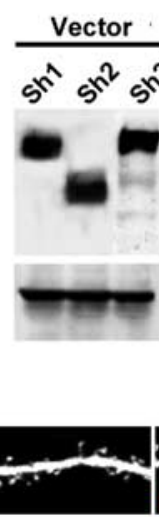

Vector
B

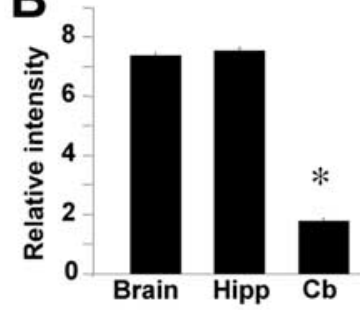

siShank3
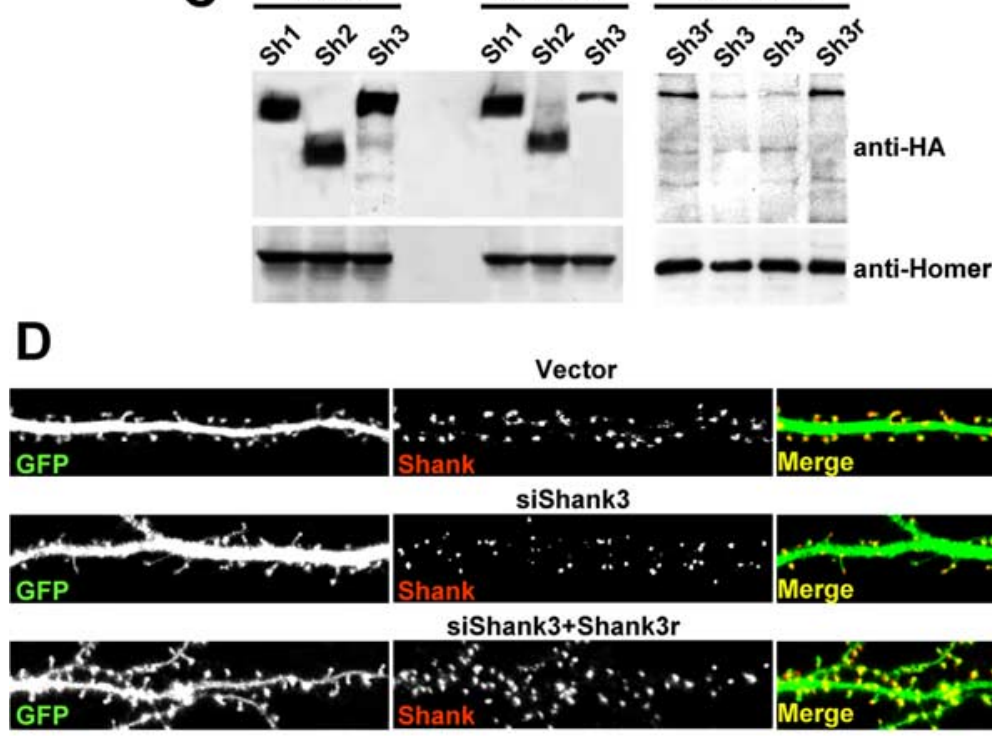

E
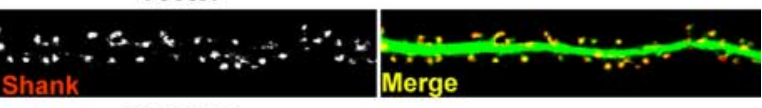

siShank3
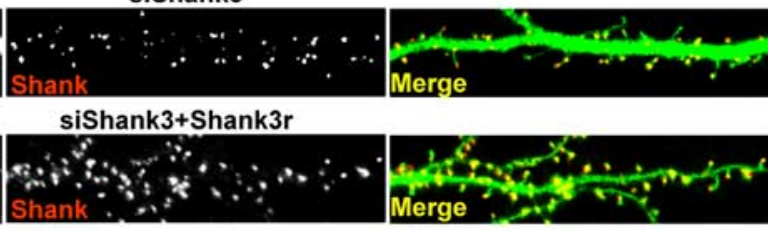

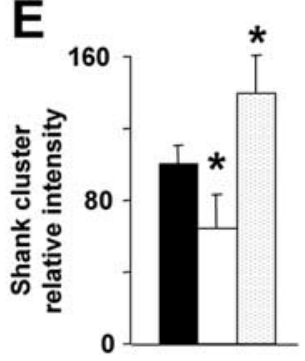

$\mathbf{F}$

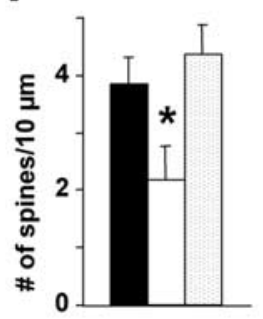

G

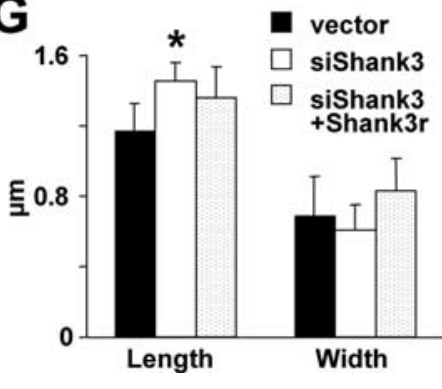

Figure 1. Shank is required for spine maintenance in hippocampal neurons. $A$, Western blot of Shank proteins obtained from adult mouse brain (left), hippocampal (Hipp; middle), and cerebellar (Cb; right) cultures. The band in the $240 \mathrm{kDa}$ region corresponds to the apparent molecular weight of Shank1. The double bands in the 160 and $200 \mathrm{kDa}$ regions may correspond to two splice variants of Shank2 and Shank3, respectively (Lim et al., 1999; Naisbitt et al., 1999; Qualmann et al., 2004). $\boldsymbol{B}$, The histogram shows the total amount of Shank protein. Each box of the histogram represents the mean ratio ( $\pm \mathrm{SEM} ; n=5$ ) over background noise taken from a nonimmunoreactive area of the Western blot. C, COS-7 cells were triple transfected with HA-Shank1B (Sh1), HA-Shank2 (Sh2), HA-Shank3 (Sh3), or HA-Shank3 carrying silent mutations (Sh3r), plus Homer1b and either an empty vector (left) or siShank3 plasmid (middle and right), as indicated on top of the panels. Two days after transfection, Western blots were performed using anti-HA and anti-Homer 1 antibodies as indicated on the right side of the panel. The right panel shows a duplicate experiment. Note that siShank3 specifically inhibits Shank3 expression, but not the other Shank genes nor the Shank3r mutated on the region recognized by the siRNA. Note that Shank1B is a short variant lacking the SAM domain of Shank1. This may explain why the Sh1 and Sh3 bands appear of similar size, as opposed to the blot in A. D, GFP fluorescence and Shank immunostaining of dendrites from cultured hippocampal neurons cotransfected with GFP and empty vector (top), or GFP and siShank3 (middle), or GFP plus siShank3 and Shank3r. $\boldsymbol{E}-\boldsymbol{G}$, Effects of siShank3 in the absence and presence of Shank3r on endogenous Shank cluster staining (E) dendritic spines density $(\boldsymbol{F})$ and length and width $(\boldsymbol{G})$, in hippocampal culture. Note that cotransfection of Shank3r rescued the spine phenotypes induced by siShank3. ${ }^{*} p \leq 0.05$.

\section{Results}

Involvement of Shank3 in dendritic spine induction and maintenance

Three-week-old cultured hippocampal neurons express Shank proteins (Fig. 1A) and display dendritic spines that contain these proteins (Fig. 1D). Treatment of these neurons with a small in- 


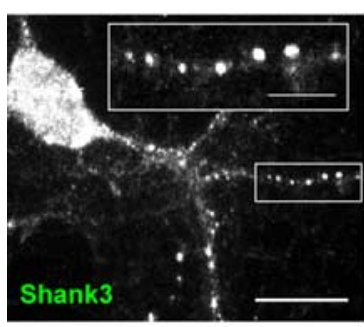

B

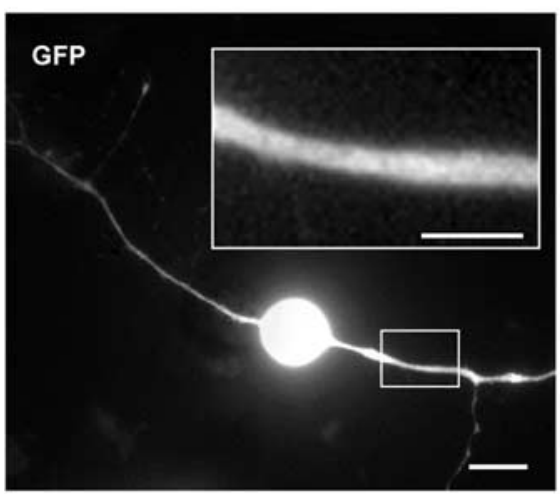

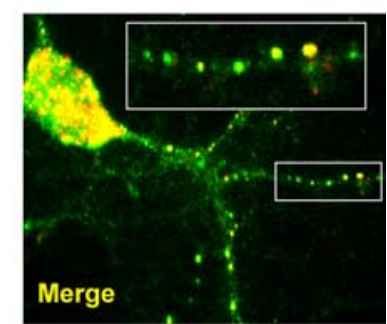

C

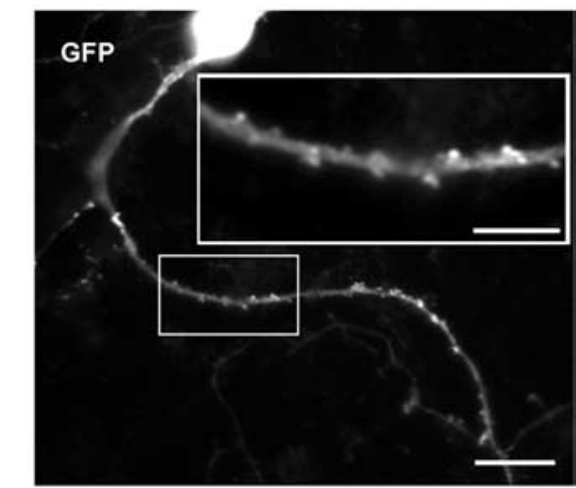

D

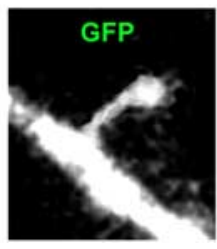

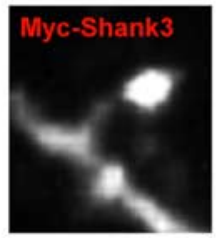

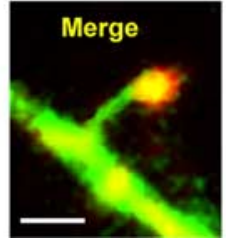

Figure 2. Transfection of Shank3 induces de novo formation of dendritic spines in CGCs. $\boldsymbol{A}$, Immunolabeling of endogenous Shank3 and PSD-95 in a CGC. Scale bars: $10 \mu \mathrm{m}$ unless otherwise specified; inset, $2.5 \mu \mathrm{m}$. B, GFP-transfected CGC. Scale bars: 5 $\mu \mathrm{m}$; inset, $3 \mu \mathrm{m}$. C, GFP fluorescence of a myc-Shank3-cotransfected CGC. Scale bar: inset, $5 \mu \mathrm{m}$. D, Typical GFP fluorescence and myc-Shank3 immunostaining of a dendritic spine from a GFP plus myc-Shank3-cotransfected CGC. Scale bar, $2.5 \mu \mathrm{m}$.

terfering RNA (siRNA) plasmid (siShank3) that inhibited the synthesis of Shank3, but not that of Homer1 (Fig. 1C), decreased the number and increased the length of dendritic spines (Fig. $1 D-G)$. These changes were not observed after transfection of an empty vector (Fig. $1 D$ ). The Shank3 plasmid (Shank3r) carrying

Table 1. Quantification of wild-type Shank3 and Shank3 mutant-induced filopodia and spines and modulatory effects of glutamate receptor antagonists

\begin{tabular}{lll}
\hline Shank & Number of spines per $100 \mu \mathrm{m}$ & (Spines/filopodia) $\times 100$ \\
\hline Shank3 & $33.3 \pm 1.5$ & 75 \\
$\Delta$ Cort & $16.9 \pm 0.8^{*}$ & $58^{*}$ \\
$\Delta$ Ank-SH3 & $25.9 \pm 1.2^{*}$ & 70 \\
$\Delta$ Nterm & $8.1 \pm 0.4^{* *}$ & $25^{* *}$ \\
Homer region & $0^{* *}$ & $0^{* *}$ \\
Cterm & $0^{* *}$ & $0^{* *}$ \\
DNQX & $6.1 \pm 0.3^{* *}$ & $35^{* *}$ \\
MK801 & $3.9 \pm 0.2^{* *}$ & $30^{* *}$ \\
CPCCOEt & $6.6 \pm 0.3^{* *}$ & $53^{*}$
\end{tabular}

Values are means \pm SEM obtained from $1300-10,500$ protrusions (except the 0 values). Shank3, Wild-type Shank3; $\Delta$ Cort, Shank3 mutant deleted of cortactin-binding site; $\Delta$ Ank-SH3, Shank3 mutant deleted of the ankyrin plus SH3 domain; $\Delta$ Nterm, Shank3 mutant deleted of the N terminus; Homer region, Homer-binding region of Shank3; Cterm, C-terminus of Shank3 containing the cortactin- and Abp1-binding sites plus SAM domain (detailed in Fig. 3A). DNQX, MK801, and CPCCOEt are antagonists of AMPA, NMDA, and mGluR1 receptors, respectively. ${ }^{*} p$ $\leq 0.05 ;{ }^{* *} p \leq 0.01$ silent mutations on the sequence region recognized by the siRNA rescued expression of Shank3 when cotransfected with siShank3 in COS-7 cells (Fig. 1C). This plasmid also rescued the dendritic spine phenotype when cotransfected with siShank3 in hippocampal neurons (Fig. $1 D$ $G)$. These results confirm that siShank3 is specific to Shank3 and indicate that Shank3 expression participates in spine maintenance in hippocampal neurons.

We found that the total amount of Shank protein expressed in mature (10-12 DIV) CGCs is significantly smaller than in mature (18-21 DIV) hippocampal neurons or adult brain (Fig. $1 A, B$ ). Figure $1 A$ shows that Western blotting of CGCs extracts results in only one band that corresponds to the apparent molecular weight of Shank3. In these neurons, Shank immunoreactivity displays a punctiform distribution that colocalizes with the synaptic markers PSD-95 (Fig. 2A), NMDAR subunit NR1 (see Fig. 5A), and synaptophysin (data not shown). As described previously, CGCs display a unique primary dendrite (microtubule-associated protein 2 positive) (Ango et al., 2000), devoid of dendritic spines (Fig. $2 B$ ). When transfected with Shank3 at 0 DIV and observed 10-12 $\mathrm{d}$ later (after maturation), these neurons exhibit dense dendritic protrusions (Fig. $2 C)$. Among these protrusions, $75 \%$ are spine-like and $25 \%$ are filopodia-like ( Table 1). The spine-like protrusions contained the transfected myc-tagged Shank3 protein (Fig. 2D). On the other hand, transfection of other postsynaptic proteins such as GKAP-1A, PSD-95, NR1 plus NR2B, Homer1b plus mGluR1a, or Homer1b plus mGluR5 did not induce protrusions in CGCs (data not shown). Qualitatively similar results were obtained with transfected Shank1. These results show that transfection of Shank protein alone is sufficient to induce de novo formation of dendritic spines in cerebellar aspiny neurons.

\section{The PDZ domain and Homer-binding site are required for} the dendritic targeting of Shank3

We reasoned that the dendritic targeting of Shank should be an important step in spine induction. Therefore, we studied the subcellular localization of different Shank3 mutants transfected in CGCs. Shank3 proteins bearing point mutations in the Homerbinding site (Fig. 3A, P1311L) (F1314C not shown) (Tu et al., 1999) or lacking of PDZ domain (Fig. $3 A, \Delta$ PDZ mutant) accumulated in the soma and poorly localized in the dendrites (Fig. $3 B, F, G)$. This indicates that Homer binding and the PDZ domain are required for the dendritic targeting of Shank3. Interestingly, the small amount of P1311L mutant that was targeted to the dendrites did not colocalize with the synaptic markers NR1 (Fig. 3F, inset) or synaptophysin (data not shown; no synaptic contact in 30 transfected dendrites). The $\Delta$ Ank-SH3 and $\Delta$ Cort mutants, which lack the ankyrin repeats-SH3 region and cortactin-binding site, respectively (Fig. $3 A$ ), localize in both 
soma and dendrites (Fig. $3 A, E$ ), indicating that the ankyrin repeats and cortactin binding per se do not play a crucial role in the dendritic targeting of Shank3. Importantly, when deletion of the ankyrin repeats-SH3 region is combined with deletion of the PDZ region (up to amino acid position 1062), the mutant (Fig. 3A, $\Delta$ Nterm) is still targeted to the dendrites (Fig. $3 E, C, D$ ). This result, together with the somatic retention of the $\triangle \mathrm{PDZ}$ mutant (Fig. $3 A, G$ ), suggests that the ankyrin repeats-SH3 region contains a somatic retention signal that is masked by the PDZ domain (Fig. 4E).

\section{Contribution of Shank3-specific} domains to dendritic spine induction and maturation

We then searched for a minimal region of Shank3 sufficient to induce both spineand filopodia-like protrusions in CGCs. Only those Shank3 mutants that localized in the dendrites (Fig. 3A) were studied here. Results are summarized in Table 1. The shortest mutant able to induce protrusions is the $\Delta$ Nterm mutant (Fig. $3 A, C, D)$. This mutant contains the Homer-binding region plus the distal C-terminal domain (Fig. 3A). Interestingly, neither of these domains alone (Fig. $3 \mathrm{~A}$, Homer region and C-term mutants) is able to induce protrusions. Within this C-terminal region, the cortactin-binding site appears to be a key, although not essential, element, because the $\Delta$ Cort mutant still induces spines but at lower density than wild-type Shank3 (Table 1). Comparison between the density of spines induced by two Shank3 mutants (Fig. 3A, Table $1, \Delta$ Ank-SH3 and $\Delta$ Nterm mutants), which differ by the presence or absence of the PDZ domain, clearly indicates that the PDZ domain plays a role in spine formation.

We then investigated the respective role of different regions of Shank3 in spine maturation. Different parameters were measured: the ratio of spines over filopodia, spine length, and spine head area. The $\Delta$ Cort mutant induces long spines (Fig. $4 A$ ) with reduced head area (Fig. 4B). Moreover, this mutant induces a low ratio of spines over filopodia (Table 1). These results suggest a major role of cortactin binding in spine maturation. The $\Delta$ Ank-SH3 mutant induces spines with normal length (Fig. $4 A$ ) but with reduced spine head area (Fig. $4 B$ ) compared with full-length Shank3, suggesting a specific role of the ankyrin repeats- $\mathrm{SH} 3$ region in spine head enlargement. The $\Delta$ Nterm mutant (Fig. $3 A$ ), which lacks both the ankyrin repeats- $\mathrm{SH} 3$ region and $\mathrm{PDZ}$ domain, induces spines with normal head (Fig. $4 B$ ) but with longer neck (Fig. $4 A$ ) and lower ratio of spines over filopodia than the
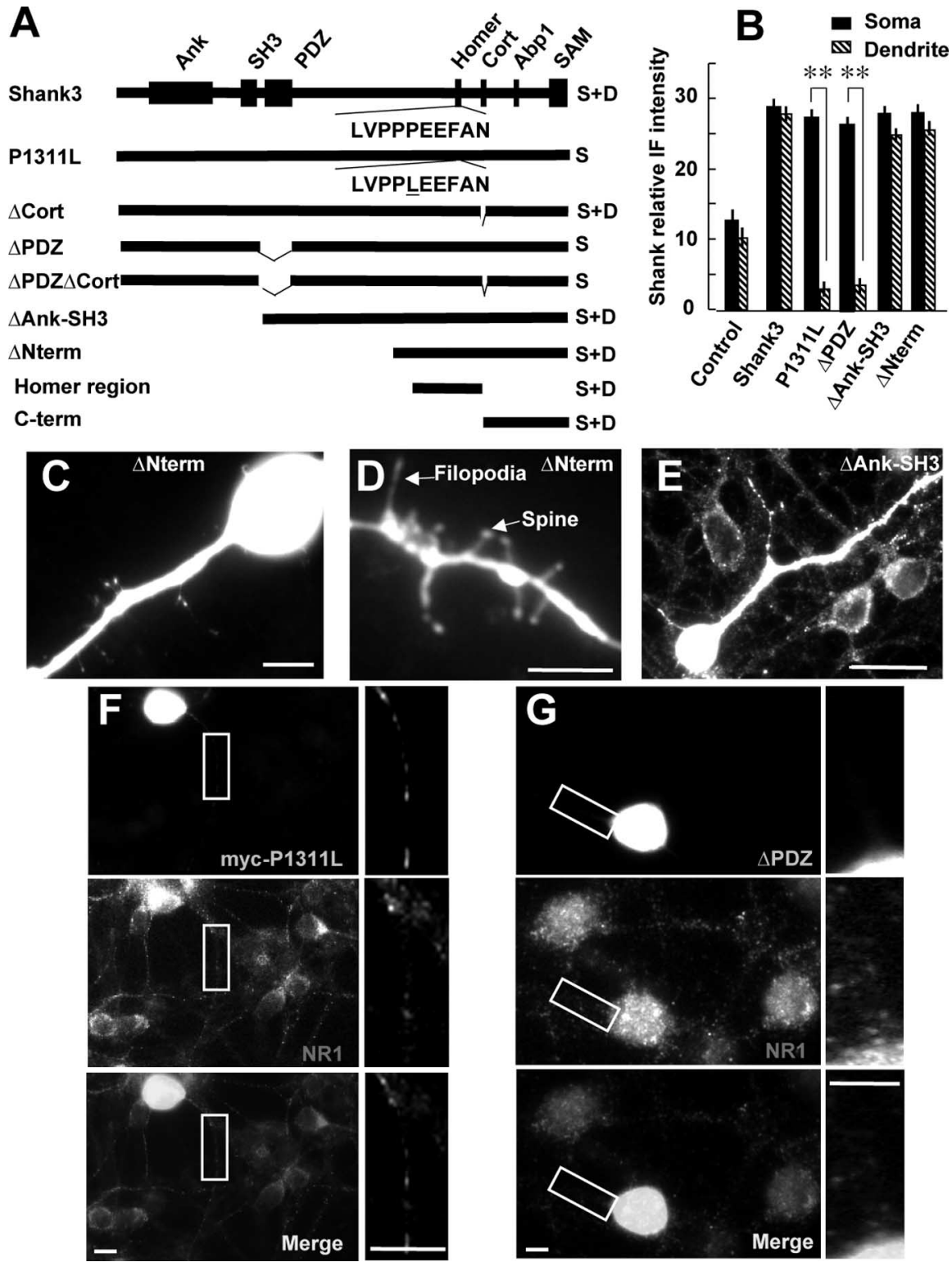

Figure 3. Subcellular localization of transfected wild-type and mutant Shank3 in CGCS. A, Diagram of Shank3 protein-protein interaction domains and Shank3 mutants. Localization of the transfected mutants (found in $>90 \%$ of randomly chosen transfected neurons; $n=40-50$ ) is indicated on the right. S, Somatic; D, dendritic; Ank, Ankyrin repeats (residues 114-347); SH3 domain (471-531); PDZ domain (566 - 663); Homer, Homer-binding site (1307-1316); Cort, cortactin-binding site (1410 1417); Abp1, Abp1-binding site (1485-1493); SAM domain (1674-1738); $\Delta$ Ank-SH3, residues 544-1373; $\Delta$ Nterm, 1063 1740; Homer region, 1143-1408; (-term, 1379-1740. B, Immunostaining intensity of endogenous Shank (control) and of transfected wild-type myc-Shank3 and mutants, measured in the soma and dendrites of $\mathrm{CGCS}$. Each bar of histogram is the mean \pm SEM of $30-40$ cells. ${ }^{* *} p \leq 0.01$. $\boldsymbol{C}-\boldsymbol{G}$, Representative somato-dendritic ( $\boldsymbol{C}, \boldsymbol{D}, \Delta$ Nterm; $\boldsymbol{E}, \Delta$ Ank-SH3) and somatic $(\boldsymbol{F}$, P1311L; $\boldsymbol{G}, \triangle$ PDZ; top) and immunostaining of the indicated transfected myc-Shank3 mutants. In $\boldsymbol{F}$ and $\boldsymbol{G}$, the middle panels represent immunostaining of the endogenous NR1 subunit, and the bottom panels are merged images of middle and top panels. The right insets are enlarged images of the framed area of the left images. Scales bars: $A-D, F, G, 5 \mu \mathrm{m} ; \boldsymbol{E}, 10 \mu \mathrm{m}$.

$\Delta$ Ank-SH3 mutant (Table 1). This result suggests that the PDZ domain plays an important role in spine maturation. These conclusions are summarized in Figure $4 E$.

\section{Glutamate receptor antagonists affect Shank3-mediated} induction of dendritic spines

Previous studies have shown that natural spines are regulated by glutamate receptor activity in the hippocampus (McKinney et al., 1999). Here, we examined whether the CGC Shank3-induced 

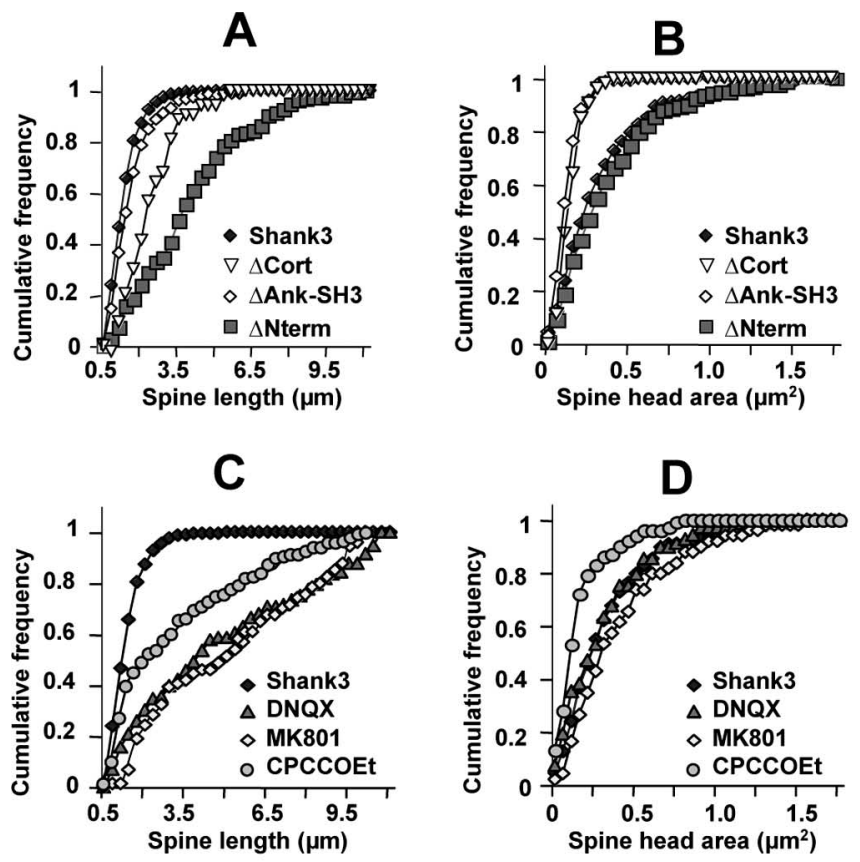

E

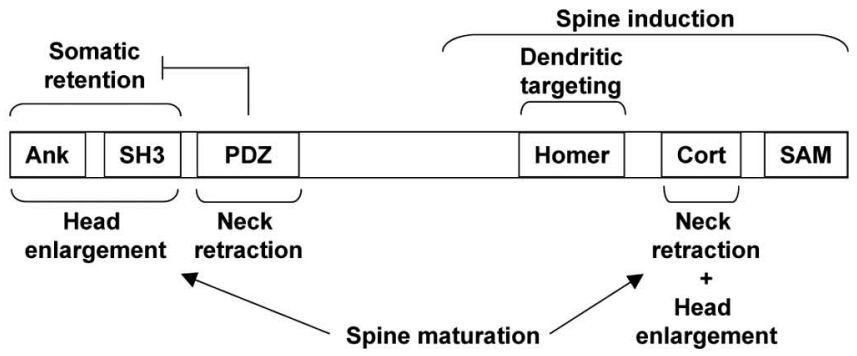

Figure 4. Shank3 mutations and glutamate receptor antagonists alter Shank3-induced spine morphology. $\boldsymbol{A}, \boldsymbol{B}$, The graphs represent cumulative distribution of length $(\boldsymbol{A})$ and head area $(\boldsymbol{B})$ of spines induced by wild-type Shank3 and indicated mutants. $\boldsymbol{C}, \boldsymbol{D}$, Cumulative distribution of length $(\boldsymbol{C})$ and head area $(\boldsymbol{D})$ of spines induced by Shank3 (wild type) in the absence and presence of the indicated glutamate receptor antagonists. $\boldsymbol{E}$, Likely functions of the Shank3-binding domains deduced from our morpho-functional studies of different Shank3 mutants, transfected in CGCs. Cort, Cortactin-binding site.

spines shared similar properties. Three days after transfection of Shank3, cultured CGCs were treated for $7 \mathrm{~d}$ with ionotropic or metabotropic glutamate receptor antagonists. All the tested glutamate receptor antagonists decreased the density of Shank3induced dendritic spines and reduced the ratio of spine/filopodia (Table 1). In the presence of the mGluR1 antagonist 7-(hydroxyimino)cyclopropa[b] chromen-1a-carboxylate ethyl ester (CPCCOEt) $(250 \mu \mathrm{M})$, transfection of Shank3 induced longer spines (Fig. 4C) with smaller head (Fig. 4D) and at significantly lower density (Table 1 ) than in the absence of the drug. Blockade of NMDARs or AMPARs with (+)-5-methyl-10,11dihydro-5H-dibenzo [a,d] cyclohepten-5,10-imine maleate (MK801) $(10 \mu \mathrm{M})$ or DNQX $(100 \mu \mathrm{M})$, respectively, increased the length (Fig. 4C) but did not affect the head area (Fig. 4D) of the Shank3-induced spines. These results show a preferential role of AMPARs and NMDARs on spine shortening and mGluR1 on spine head enlargement suggesting a concerted action of these receptors in spine maturation. Furthermore, they show that the pharmacological sensitivity of the Shank3-induced spines in CGCs resemble that of naturally existing hippocampal spines
(Halpain et al., 1998; McKinney et al., 1999; Luscher et al., 2000; Hering and Sheng, 2001; Sala et al., 2001).

\section{Shank3 recruits functional endogenous glutamate receptors}

Given the sensitivity of Shank3-induced spines to glutamate receptor antagonists, we examined whether Shank3 recruits functional endogenous glutamate receptors in CGCs. Transfected Shank3 increases immunoreactivity for the endogenous NMDAR subunit NR1 [Fig. 5, compare $A, B$; also compare $C$ (nontransfected neuron) with $B, D$ ] and AMPAR subunits GluR1/2/3 (Fig. $5 E$ ), but not $\mathrm{GABA}_{\mathrm{A}}$ receptors (data not shown), in both cell body and dendritic spines. This suggests that Shank3 selectively recruits ionotropic glutamate receptors. Transfection of the $\Delta$ Nterm mutant decreases NR1 (Fig. $5 C, D$, compare transfected and nontransfected neurons) and GluR1/2/3 (Fig. 5E) immunoreactivity in both compartments, suggesting that the recruitment of NMDARs and AMPARs depends on their interaction with the $\mathrm{N}$ terminus (most likely the PDZ domain) of Shank3.

We then verified the functionality of the Shank3-recruited glutamate receptors using patch-clamp recording of NMDAR and AMPAR whole-cell currents in transfected CGCs. Transfection of Shank3 induces a 10-fold increase in the density of both NMDAR and AMPAR currents compared with control neurons (transfected with GFP alone). On the other hand, transfection of the $\Delta$ Nterm mutant induces a threefold decrease in these currents (Fig. $6 A-C$ ), suggesting a dominant-negative effect of this mutant. This further confirms the importance of the N-terminal domain of Shank3 in the functional recruitment of ionotropic glutamate receptors. These changes did not significantly affect the ratio of NMDAR/AMPAR current density $(2.1 \pm 0.3$ in control; $1.8 \pm 0.1$ in Shank3 transfected; $1.95 \pm 0.35$ in $\Delta$ Nterm transfected CGCs; $n=10$ for each condition).

The Shank3-induced increase in NMDAR whole-cell current could result from an increase in the number of functional receptors as suggested by the immunostaining results but also from alteration in single-channel conductance and/or channel gating properties. We performed cell-attached recordings of single NMDARs with $100 \mu \mathrm{M}$ NMDA in the recording pipette. The number of single-channel open levels was consistently higher in Shank3-transfected (three to four levels) than control (one to two levels) CGCs. Current-voltage relationships revealed no significant difference in single-channel conductance in control (56 \pm 2 pS; $n=6)$, Shank3- $(59 \pm 2 \mathrm{pS} ; n=8)$, and $\Delta$ Nterm-transfected $(57 \pm 3 \mathrm{pS} ; n=10)$ CGCs (Fig. $6 D$ ). The average NMDAR singlechannel open probability was also not significantly different in control $(0.020 \pm 0.002 ; n=10)$, Shank3- $(0.028 \pm 0.007 ; n=$ $10)$, and $\Delta$ Nterm-transfected neurons $(0.020 \pm 0.002$; $n=10)$. These data further indicate that Shank3 increases NMDAR current density by recruiting new functional NMDARs rather than by affecting biophysical properties of existing functional NMDARs. Because this effect requires the $\mathrm{N}$-terminal domain of Shank3, the recruitment of NMDARs probably depends on interaction of the channel complex with the Shank3 PDZ domain.

We also examined whether Shank3 recruits functional mGluR1 receptors. Mouse CGCs express mGluR1a (Ango et al., 1999), and transfection of Shank3 in these neurons increased the receptor immunoreactivity in both soma and spines, whereas transfection of the Shank3-P1311L mutant, which does not interact with the Homer-mGluR1a complex (Tu et al., 1999), induced the opposite effect (Fig. 7 A,B). Pharmacological stimulation of mGluRla results in intracellular $\mathrm{Ca}^{2+}$ release and 
activation of the BK channel. Po of this channel recorded in cell-attached patches thus correlates to mGluRla activation in CGCs (Fagni et al., 1991). Transfection of Shank3 significantly increased the mGluR1-induced BK channel openings evoked by bath application of the mGluR1 agonist 3,4-dihydroxyphenylglycol (DHPG) $(400 \mu \mathrm{M})$, whereas the Shank3-P1311L mutant induced the opposite effect (Fig. 7C). These results show that Shank3 recruits functional mGluRla receptors, and this effect requires interaction of Shank3 with Homer. We verified that neither wild-type Shank3 nor Shank3 mutants (Fig. 7D, $\Delta$ term) (P1311L not shown) affected $\mathrm{GABA}_{\mathrm{A}}$ receptor current. Together, these results show that Shank3 selectively recruits new functional glutamate receptors.

\section{Shank 3 induces formation of new functional synapses}

Shank3 induces de novo spines and recruits glutamate receptors, but this does not necessarily mean that the new Shank3induced spines are functional. Therefore, we investigated whether axon terminals contacted these de novo dendritic spines. Dendrites of control CGCs display antisynaptophysin immunopositive puncta (data not shown) indicating the existence of axo-dendritic contacts on these neurons, although they do not exhibit dendritic spines. Transfection of Shank3 significantly increases the number and size $\left(0.24 \pm 0.06 \mu \mathrm{m}^{2}\right.$ in control and $0.58 \pm$ $0.15 \mu \mathrm{m}^{2}$ in transfected CGCs; $n=30$ for each condition) of the synaptophysinimmunopositive puncta. Moreover, 66\% of the Shank3-induced spines were contacted by axon terminals, as assessed by their colocalization with synaptophysin. Conversely, transfection of the $\Delta$ Nterm mutant significantly decreases the number and size $\left(0.09 \pm 0.05 \mu \mathrm{m}^{2} ; n=30\right)$ of these contacts. No axonal contact was found on protrusions (spines and filopodia) induced by the $\Delta$ Nterm mutant (Fig. $8 A$ ). These results indicate that transgene expression of Shank3 induces novel and larger synaptic contacts, including on the de novo formed spines, and this effect requires the $\mathrm{N}$ terminus of the protein.

We then investigated whether the newly formed synapses are functional. Whole-cell patch-clamp recordings performed in control CGCs revealed a rare occurrence of mEPSCs (Fig. $8 \mathrm{~B}$ ) and low-frequency spontaneous EPSCs (Fig. 8D). Transfection of Shank3 significantly increases the frequency and amplitude of these events (Fig. 8C,E; Table 2), suggesting that the new synaptic contacts are functional. These results are consistent with our immunocytochemical studies (Fig. 5).

We then examined whether Shank3 recruits functional
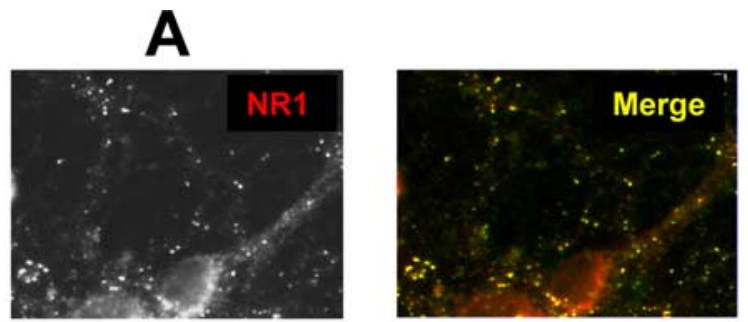

B
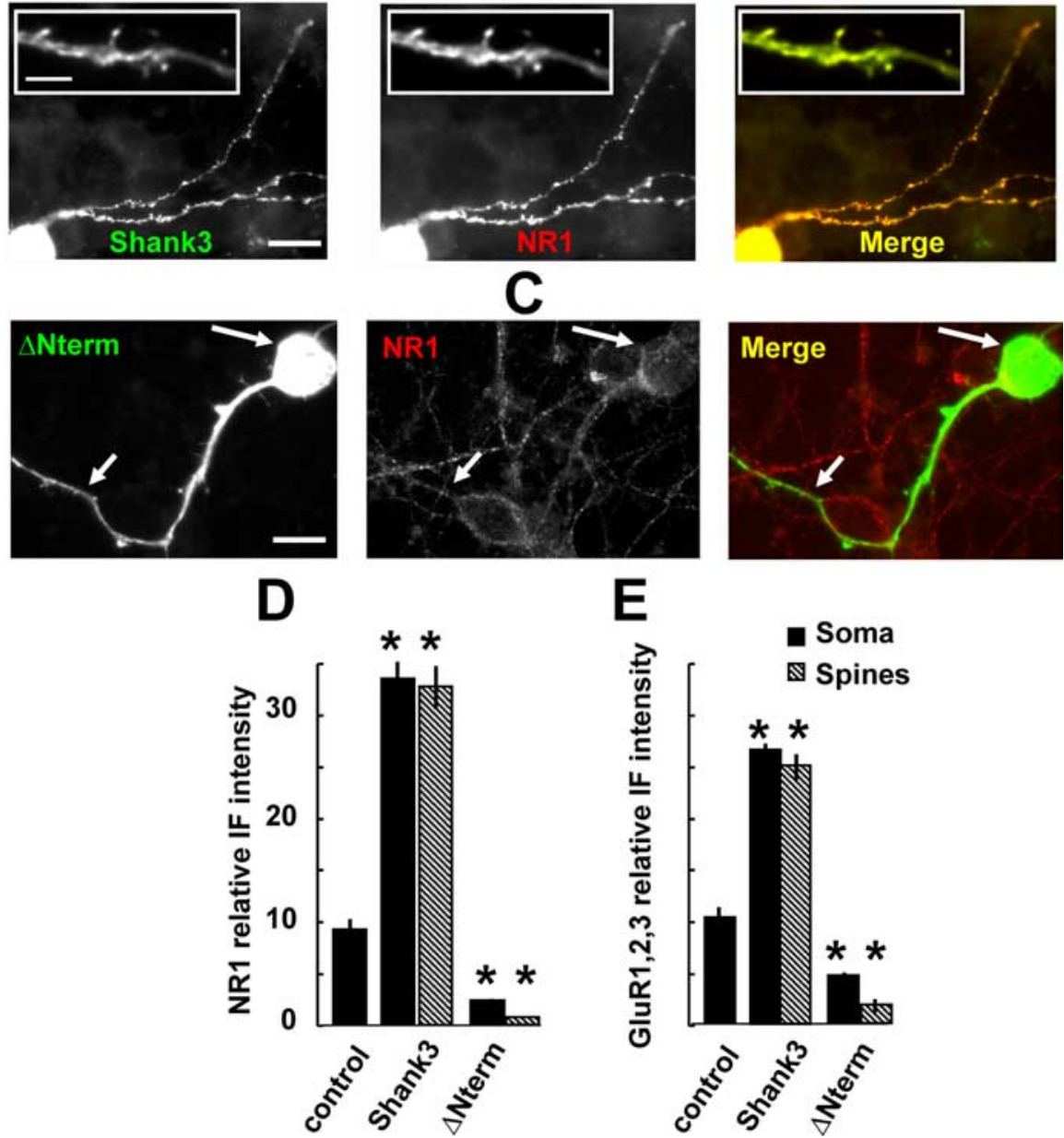

Figure 5. Transfected Shank3 recruits NMDARs and AMPARs. $\boldsymbol{A}$, Immunolabeling of endogenous Shank and endogenous NR1 subunit in a nontransfected cerebellar culture. $\boldsymbol{B}$, Shank3 and endogenous NR1 immunostaining from a Shank3-transfected CGC. Level intensity of the image has been reduced for optimal visualization of Shank3 (left) and NR1 (middle) immunofluorescent labeling. As a consequence, the Shank and NR1 immunolabeling in nontransfected neurons present in the same field cannot be seen because of its to low intensity. Insets are enlarged images of a dendrite from another Shank3-transfected CGC showing colocalization of transfected Shank3 and endogenous NR1 in the de novo spine. C, GFP fluorescence and endogenous NR1 immunostaining from a cerebellar culture cotransfected with GFP plus $\Delta$ Nterm mutant. Arrows indicate soma and dendrite of the same cotransfected CGC. Scale bars, $10 \mu \mathrm{m}$. $\boldsymbol{D}, \boldsymbol{E}$, Immunostaining intensity of endogenous NR1 and GluR1/2/3 in control CGCs and Shank3- or $\Delta$ Nterm-transfected CGCs. Each bar of histogram is the mean \pm SEM of $40-50$ cells. ${ }^{*} p \leq 0.05$.

postsynaptic AMPARs and/or NMDARs at the newly formed synaptic sites. It is generally assumed that the decay kinetics of mEPSCs in mature CGC can be fitted by a double-exponential relationship with fast and slow time constants corresponding to the AMPAR and NMDAR components, respectively (CullCandy et al., 2001; Losi et al., 2002). In our study, a majority (11 over 17) of nontransfected CGCs displayed mEPSC decay that could be best fitted with only single slow exponential relationships (Table 2, $\tau_{1}$ solely), suggesting the presence of functional 


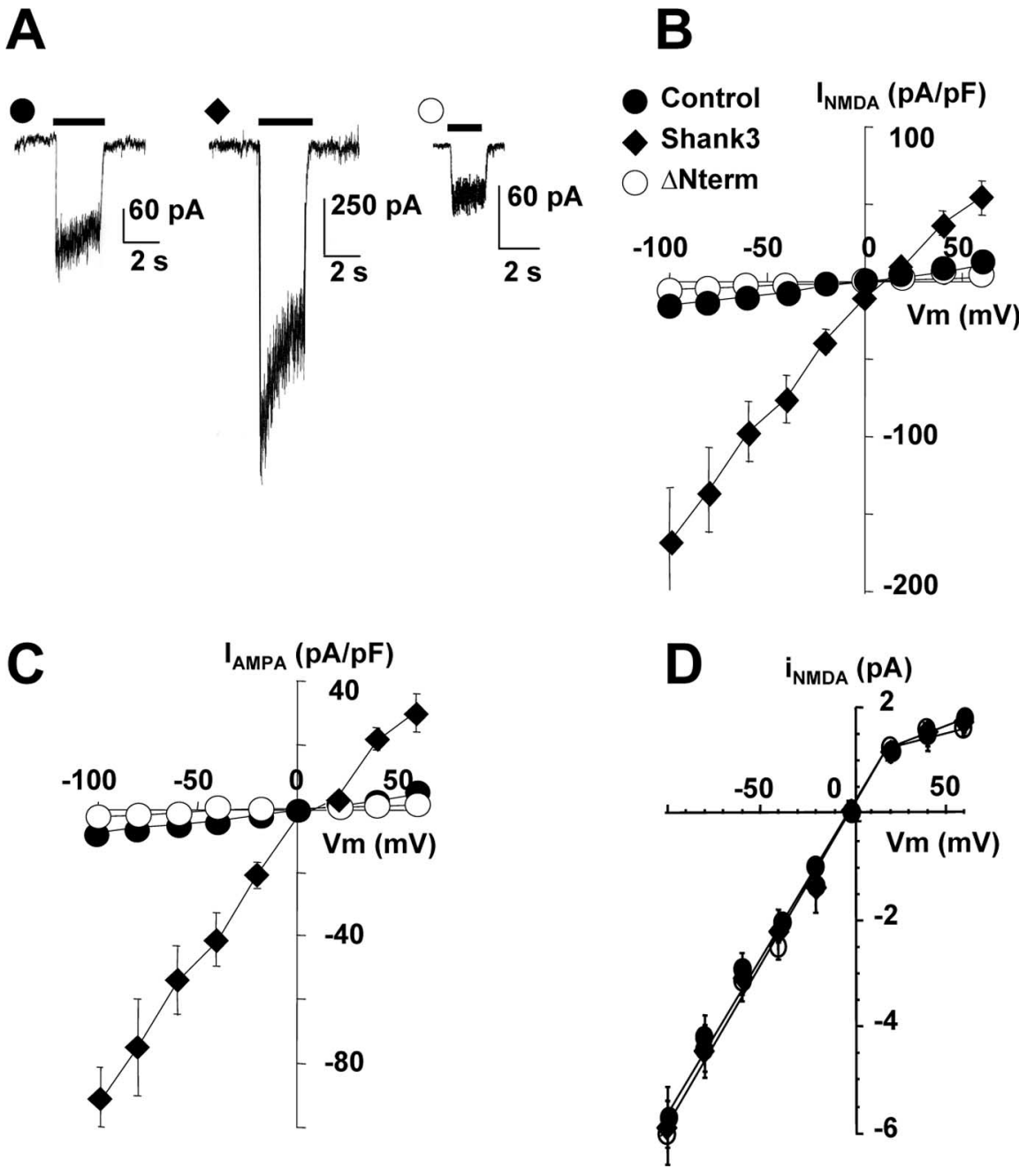

Figure 6. The Shank3-recruited NMDARs and AMPARs are functional. $\boldsymbol{A}$, NMDAR whole-cell currents recorded in control (left), Shank3- (middle), and $\Delta$ Nterm- (right) transfected CGCs at $-65 \mathrm{mV}$. B, D, Current density-voltage (I-V) relationships of whole-cell NMDARs $(\boldsymbol{B})$ and AMPARs $(\boldsymbol{C} ; n \geq 10$ each). The current density measured at $-80 \mathrm{mV}$ in control and $\Delta$ Ntermtransfected neurons was $15 \pm 5$ and $5 \pm 0.5 \mathrm{pA} / \mathrm{pF}$ in $\boldsymbol{B}$ and $7.1 \pm 1.6$ and $2.5 \pm 0.5 \mathrm{pA} / \mathrm{pF}$ in $\boldsymbol{C}$. $\boldsymbol{D}, 1-V$ relationships of cell-attached recorded single NMDAR channels $(n \geq 10)$. I-V curves obtained in Shank3- and $\Delta$ Nterm-transfected neurons were significantly different from those obtained from control neurons, except in $\boldsymbol{D}$.

receptors and are reminiscent of synaptic maturation in CGCs (Cull-Candy et al., 2001; Losi et al., 2002).

\section{Discussion}

The central observations of this study are that knock-down of Shank in spiny (hippocampal) neurons decreases spine density, whereas transfection of this protein in aspiny (CGCs) neurons induces formation of dendritic spines with functional synapses. These losses and gains of function suggest that Shank proteins play an important role in de novo formation of functional spines. Accordingly, CGCs provide a valuable model to study molecular mechanism by which Shank proteins induce spinogenesis. Here, we use this model to define the structure-function relationships for Shank3 in spine formation and glutamate signaling properties.

We focused our studies on Shank3 because this protein is the only detectable endogenous Shank subtype in CGCs, both in culture (present study) and in situ (Böckers et al., 2004). The Shank3-induced formation of spines in CGCs is likely to result from a specific effect of the protein. (1) Shank3 mutants that accumulate in the soma of CGCs do not induce ectopic somatic spines; (2) Shank3 mutants that also accumulate in dendrites do not necessarily induce spines; (3) the effects of glutamate receptor antagonists on Shank3-induced spines in CGCs are comparable with those generally observed on the naturally existing hippocampal spines (Halpain et al., 1998; McKinney et al., 1999; Luscher et al., 2000; Hering and Sheng, 2001; Sala et al., 2001).

Little is known about the mechanism of spine induction. There is a debate over whether spine induction depends solely on intrinsic factors or on presynaptic inner-

postsynaptic NMDARs only (and absence of AMPARs). In support of this hypothesis, the NMDAR antagonist MK801 $(10 \mu \mathrm{M})$ completely and reversibly inhibited the synaptic events (data not shown). In contrast, in 100\% of the Shank3-transfected CGCs, mEPSCs were best fitted with double (fast and slow) exponential decay (Table 2) and were partially inhibited by MK801 or the AMPAR antagonist DNQX (100 $\mu \mathrm{M}$; data not shown). The weight of the fast $\left(A_{0}\right)$, but not slow $\left(A_{1}\right)$, component of these mEPSCs, and therefore the ratio of AMPAR over NMDAR synaptic currents $\left(A_{0} / A_{1}\right)$, increased (Table 2$)$, suggesting that transfection of Shank3 caused incorporation of more functional postsynaptic AMPARs than NMDARs, as it is the case during synapse maturation. Finally, the decay time constant of the slow component $\left(\tau_{1}\right)$ became significantly faster (Table 2), a fact which has been attributed previously to modification in NMDAR subunit composition, in developing CGCs (Cull-Candy et al., 2001; Losi et al., 2003). Collectively, the changes in amplitude, frequency, and kinetics of mEPSCs observed after transfection of Shank3 reflect postsynaptic recruitment of functional glutamate vation as well (Yuste and Bonhoeffer, 2004). It has been reported previously that expression of the $\mathrm{N}$-terminal domain of the AMPAR GluR2 subunit is sufficient to induce spines in hippocampal aspiny neurons (Passafaro et al., 2003), suggesting that postsynaptic extracellular factors can induce spinogenesis. Our results clearly indicate that a postsynaptic, but intracellular, scaffolding protein is also sufficient to trigger spinogenesis, at least under conditions of transgene expression in CGCs. The most striking result of our study is that this single protein, probably in concert with several other proteins, can orchestrate a complete program of spinogenesis, including spine induction, maturation (retraction of filopodia and spine head enlargement), and recruitment of functional glutamate receptors. This role of spine organizer is associated with formation of functional synapses. Indeed, we found that transfection of Shank3 not only increases the frequency but also amplitude and the AMPA component of mEPSCs, as well as the number and size of synaptic contacts, including at the level of the induced spines. Therefore, the de novo dendritic 


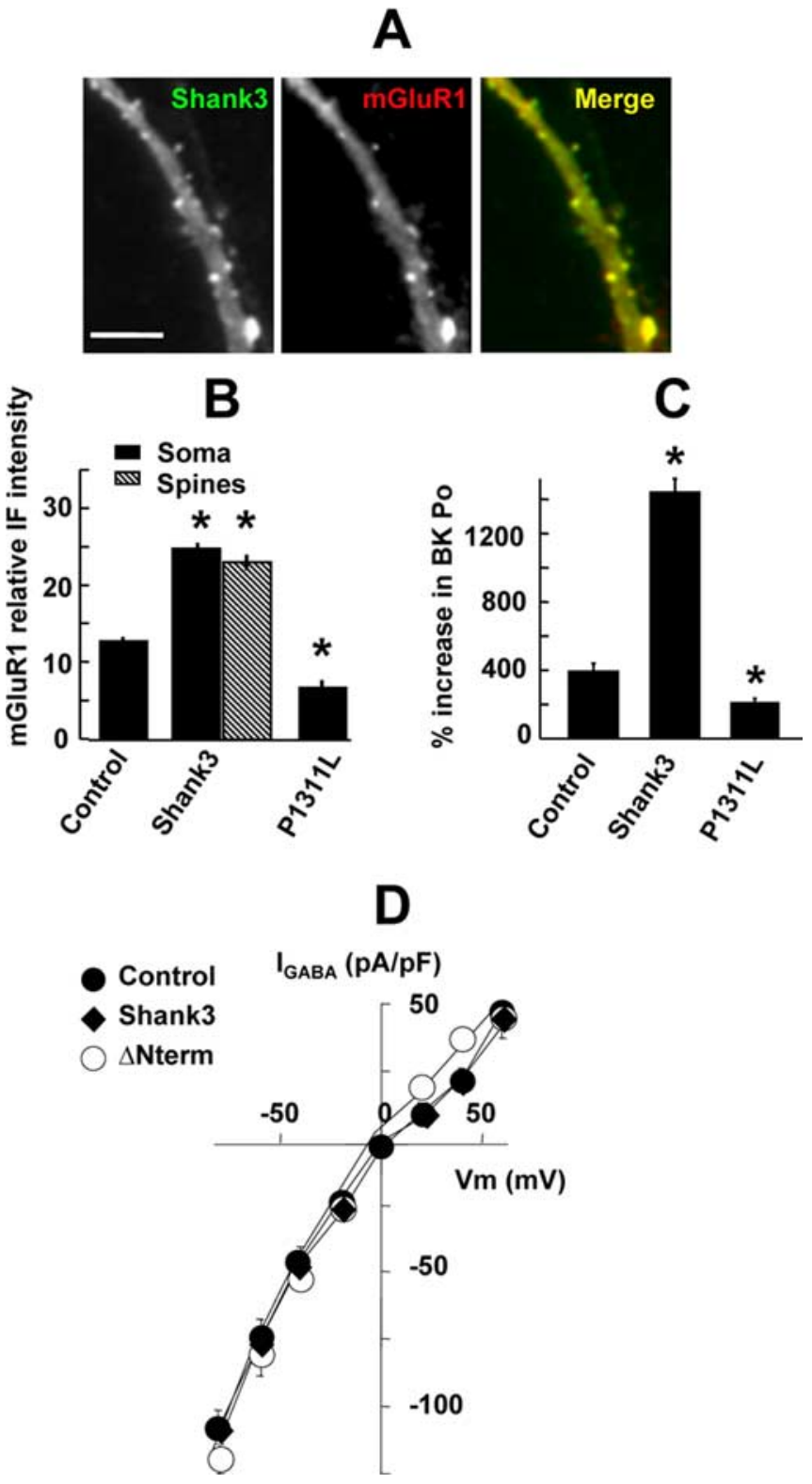

Figure 7. Transfected Shank3 recruits endogenous mGluR1. A, Shank3 and endogenous mGluR1 immunostaining of a Shank3-transfected CGC dendrite. Scale bar, $10 \mu \mathrm{m} . \boldsymbol{B}$, Immunostaining intensity of endogenous mGluR1 in control CGCs and Shank3- or P1311Ltransfected CGCs. Each bar of the histogram is the mean \pm SEM of $40-50$ cells. C, Percentage increase in BK channel $P_{0}$ induced by DHPG application in control, Shank3-, and P1311L-transfected CGCs. Each bar of histogram is the mean \pm SEM of seven cells. ${ }^{*} p \leq$ 0.05. D, Absence of effect of transfected Shank3 and Shank3 mutant on I-V relationships of $\mathrm{GABA}_{\mathrm{A}}$ receptor $(n \geq 10)$.

spines are functional, implicating stabilization of axon terminals onto the newly formed dendritic spines. A similar effect has been described in cultured hippocampal neurons after transfection of Shank1 or PSD-95 and has been attributed to induction of an unidentified retrograde signal (El-Husseini et al., 2000; Sala et al., 2001). A same hypothesis may therefore apply here to transfection of Shank3 in CGCs.

Despite its prominent effects, expression of Shank3 transgene is not the sole determinant of spine formation, because the process is still modulated by inotropic and metabotropic glutamate receptor activity. Because Shank3 recruits these receptors to den- dritic spines in a functional manner, these receptors may be activated by ambient glutamate, including glutamate released at the newly formed axonal contact. Thus, a secondary cooperative effect may exist between Shank and glutamate receptors during maturation of a nascent spine in a feedforward mechanism. Whether the recruitment and localization of glutamate receptors is also a primary mechanism underlying the effect of Shank3 on spine formation remains to be determined.

We intended to dissect the respective roles of the different domains of Shank in spine formation using a mutagenesis approach. This method carries the caveat of all deletion/mutation analyses, which is that mutations of one domain may affect the structure and/or function of the entire protein. Nevertheless, we can tentatively propose some specific roles for different regions of Shank (Fig. $4 E$ ). We found a minimal region of Shank3 able to induce dendritic spines. This region contains the Homer and cortactin-binding sites, as well as the SAM domain. The Homer-binding site is essential for the dendritic targeting of Shank3 in CGCs (present study) and regulates postsynaptic clustering of Shank1 in hippocampal neurons (Sala et al., 2003). This site is also important for the postsynaptic recruitment of mGluR1 in CGCs. The SAM domain allows multimerization (Naisbitt et al., 1999; Böckers et al., 2002) and probably accumulation of Shank at postsynaptic sites. The cortactin interaction site of Shank per se is not essential for induction of dendritic protrusions. Consistent with this result, overexpression of cortactin has been reported to induce new spines in hippocampal neurons, but this activity occurs independently of its interaction with Shank (Hering and Sheng, 2003). On the other hand, we found that the cortactin-binding site as well as the ankyrin repeats-SH3 region of Shank play a major role in spine maturation. The cortactin-binding site controls both retraction and head enlargement of spines, whereas the ankyrin repeats-SH3 region controls spine enlargement solely. Interestingly, F-actin, which binds cortactin, is present in both the neck and head of the spines, whereas spectrin, which binds the ankyrin repeats of Shank (Boeckers et al., 2001), is enriched in the head of the spines (Malchiodi-Albedi et al., 1993; Ursitti et al., 2001). The PDZ domain is involved in the dendritic targeting of Shank3 in CGCs (present study) and for Shank1 synaptic targeting in cultured hippocampal neurons (Romorini et al., 2004). In addition, we show here that this domain is essential for maturation of spines, as well as synaptogenesis in CGCs, certainly because of its ability to bind and accumulate ionotropic and metabotropic glutamate receptors in a functional manner. It is important to note that in these studies, we used a Shank3 mutant ( $\Delta$ Nterm construct) bearing a large deletion of the $\mathrm{N}$-terminal domain that comprises a region flanking the PDZ domain (residues 663-1063) for which there is no identifiedprotein-binding domain. This region might as well participate in spine induction.

Low expression of Shank1 has been correlated with poor spine development in immature cultured hippocampal neurons (Boeckers et al., 1999; Lim et al., 1999; Sala et al., 2001). We found that the endogenous level of Shank protein in CGCs is low compared with cultured hippocampal neurons. Therefore, the absence of spine and low synaptic activity in CGCs may result from the low-level native expression of Shank proteins in these neurons. Based on this hypothesis, one can speculate that evolutionary mutation of the Shank gene promoter that would 


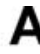

A
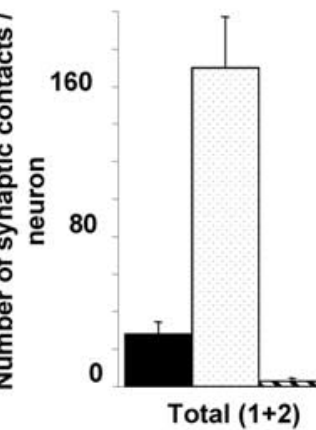

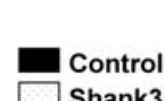

Shank3 NV $\Delta$ Nterm
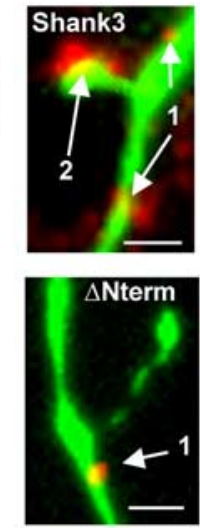

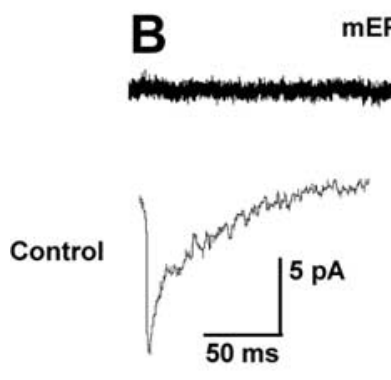

C

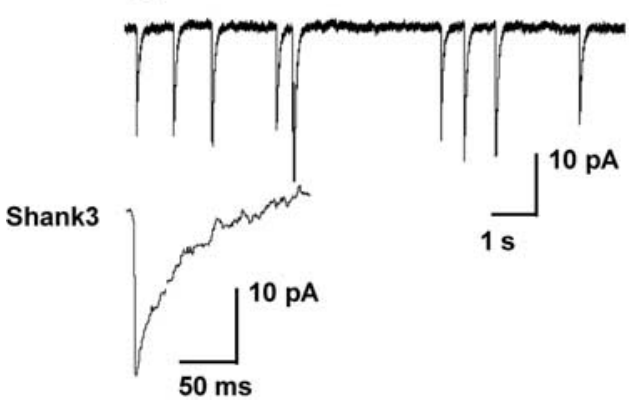

D

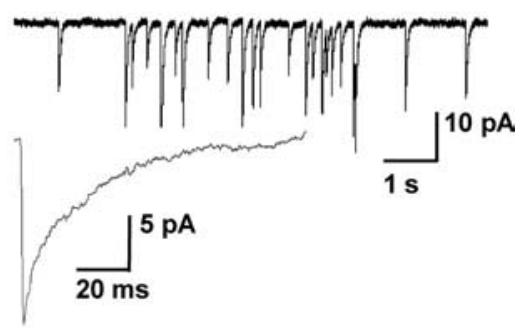

E

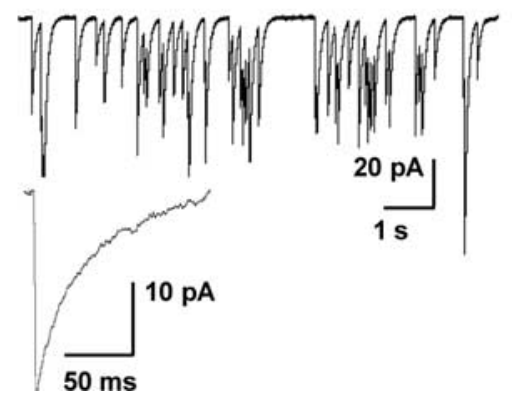

Figure 8. Transfected Shank3 induces formation of new functional synapses. $\boldsymbol{A}$, The histogram represents the number of synaptic contacts per CGC in control (absence of spine), Shank3-, and $\Delta$ Nterm-transfected cultures ( $n \geq 30$ ). Insets are merged image of GFP fluorescence (green) and anti-synaptophysin immunostaining (red) from a wild-type Shank3 plus GFP (top) and Shank3 $\Delta$ Nterm mutant plus GFP-cotransfected CGC dendrites. Note the presence of synaptic contacts (yellow area) on dendritic shaft (arrow 1) and spine (arrow 2) with Shank3 and the absence of type 2 (on spine) contact with $\Delta$ Nterm mutant. Scale bar, 2.5 $\mu \mathrm{m}$. Error bars represent SEM. $\boldsymbol{B}, \boldsymbol{C}, \mathrm{mEPSC}$ s recorded at $-65 \mathrm{mV}$ in control $(\boldsymbol{B})$ and Shank3-transfected (C) CGCS. Insets represent expanded averaged events $(n \geq 50)$. D, $\boldsymbol{E}$, Same as in $\boldsymbol{B}$ and $\boldsymbol{C}$, but for sEPSCS.

result in enhanced protein expression in a group of aspiny neurons may turn them into spiny neurons with new functional properties. Thus, Shank would appear as an ideal structural master gene candidate for evolution.
Our study also provides putative structural basis for the 22q13 mental retardation syndrome. As pointed out in the Introduction, this syndrome is correlated to haploinsufficiency of the Shank3 gene (Bonaglia et al., 2001; Wilson et al., 2003). Analysis of two patients revealed that breakpoints in the Shank3 gene were at positions between the ankyrin repeats and $\mathrm{SH} 3$ domain in one patient (Wilson et al., 2003) and between the PDZ domain and Homer-binding site the other patient (Bonaglia et al., 2001). One can predict that such mutations would result in either lack of expression of the Shank3 protein, or at best in expression of Shank3 fragments, which according to our results should not be targeted to the dendrites. We can tentatively suggest that the 22q13 deletion mental retardation patients should display low-density and immature elongated spines. Such modifications are characteristics of the majority of mental retardation syndromes (Irwin et al., 2000) and would explain the altered cognitive performances observed in these patients.

\section{References}

Ango F, Albani-Torregrossa S, Joly C, Robbe D, Michel JM, Pin JP, Bockaert J, Fagni L (1999) A simple method to transfer plasmid DNA into neuronal primary cultures: functional expression of the mGlu5 receptor in cerebellar granule cells. Neuropharmacology 38:793-803.

Ango F, Pin JP, Tu JC, Xiao B, Worley PF, Bockaert J, Fagni L (2000) Dendritic and axonal targeting of type 5 metabotropic glutamate receptor is regulated by Homerl proteins and neuronal excitation. J Neurosci 20:8710-8716.

Böckers TM, Bockmann J, Kreutz MR, Gundelfinger ED (2002) ProSAP/Shank proteins—a family of higher order organizing molecules of the postsynaptic density with an emerging role in human neurological disease. J Neurochem 81:903-910.

Böckers TM, Segger-Junius M, Iglauer P, Bockmann J, Gundelfinger ED, Kreutz MR, Richter D, Kindler S, Kreienkamp H-J (2004) Differential expression and dendritic transcript localization of Shank family members: identification of a dendritic targeting element in the $3^{\prime}$ untranslated region of Shank1A mRNA. Mol Cell Neurosci 26:182-190.

\section{Table 2. Effects of Shank3 transfection on mEPSC and SEPSC}

\begin{tabular}{|c|c|c|c|c|c|c|c|c|c|}
\hline & $\begin{array}{l}\text { Amplitude } \\
\text { (pA) }\end{array}$ & $\begin{array}{l}\text { Frequency } \\
(\mathrm{Hz})\end{array}$ & $\tau_{\text {fast }}\left(\tau_{0}\right)$ & $\tau_{\text {slow }}\left(\tau_{1}\right)$ & $A_{\text {fast }}\left(A_{0}\right)$ & $A_{\text {slow }}\left(A_{1}\right)$ & $\begin{array}{l}A_{\text {fast }} / A_{\text {slow }} \\
\left(A_{0} / A_{1}\right)\end{array}$ & $n$ & \\
\hline \multicolumn{10}{|l|}{ mEPSC } \\
\hline \multirow[t]{2}{*}{ Control } & $8.0 \pm 0.6$ & $0.1 \pm 0.01$ & n.e. & $100.9 \pm 9.6$ & 0 & $14.8 \pm 1.4$ & 0 & 11 & 17 \\
\hline & & & $5.7 \pm 0.3$ & $106.1 \pm 13.1$ & $2.4 \pm 1.0$ & $14.6 \pm 1.2$ & $0.16 \pm 1.2$ & 6 & \\
\hline Shank3 & $18.9 \pm 3.3^{* *}$ & $2.5 \pm 0.2^{* *}$ & $4.8 \pm 2.5$ & $45.5 \pm 8.7^{* *}$ & $10.0 \pm 1.7^{* *}$ & $16.3 \pm 1.2$ & $0.61 \pm 2.0^{* *}$ & 19 & \\
\hline \multicolumn{9}{|l|}{ sEPSC } & \\
\hline Control & $16.7 \pm 3.4$ & $1.1 \pm 0.2$ & n.d. & n.d. & n.d. & n.d. & n.d. & 19 & \\
\hline Shank3 & $27.5 \pm 2.0^{*}$ & $5.8 \pm 0.3^{*}$ & n.d. & n.d. & n.d. & n.d. & n.d. & 12 & \\
\hline
\end{tabular}

Each value is the mean \pm SEM obtained from the indicated number of neurons $(n)$. The recorded $\mathrm{mEPSC}$ and sEPSCs were best fitted with either single- or double-exponential relationships of the following type: $I=A_{0}$ exp $\left(-t / \tau_{0}\right)+A_{1}$ $\exp \left(-t / \tau_{1}\right)+C$. Note that for the mEPSC studies, over 17 control neurons, 11 displayed mEPSCs with slow time constant $\left(\tau_{1}\right)$ single-exponential decay, and only six displayed $m E P S C s$ with double $\left(\tau_{0}\right.$ and $\left.\tau_{1}\right)$-exponential decay. n. e., Nonexisting fast decay component; $n$. d., not determined. ${ }^{*} p \leq 0.05 ;{ }^{* *} p \leq 0.01$. 
Boeckers TM, Winter C, Smalla KH, Kreutz MR, Bockmann J, Seidenbecher C, Garner CC, Gundelfinger ED (1999) Proline-rich synapse-associated proteins ProSAP1 and ProSAP2 interact with synaptic proteins of the SAPAP/GKAP family. Biochem Biophys Res Commun 264:247-252.

Boeckers TM, Mameza MG, Kreutz MR, Bockmann J, Weise C, Buck F, Richter D, Gundelfinger ED, Kreienkamp HJ (2001) Synaptic scaffolding proteins in rat brain. Ankyrin repeats of the multidomain Shank protein family interact with the cytoskeletal protein alpha-fodrin. J Biol Chem 276:40104-40112.

Bonaglia MC, Giorda R, Borgatti R, Felisari G, Gagliardi C, Selicorni A, Zuffardi O (2001) Disruption of the ProSAP2 gene in a $\mathrm{t}(12 ; 22)(\mathrm{q} 24.1$; q13.3) is associated with the 22q13.3 deletion syndrome. Am J Hum Genet 69:261-268.

Brummelkamp TR, Bernards R, Agami R (2002) A system for stable expression of short interfering RNAs in mammalian cells. Science 296:550-553.

Cull-Candy S, Brickley S, Farrant M (2001) NMDA receptor subunits: diversity, development and disease. Curr Opin Neurobiol 11:327-335.

Ehlers MD (2002) Molecular morphogens for dendritic spines. Trends Neurosci 25:64-67.

El-Husseini AE, Schnell E, Chetkovich DM, Nicoll RA, Bredt DS (2000) PSD-95 involvement in maturation of excitatory synapses. Science 290:1364-1368.

Engert F, Bonhoeffer T (1999) Dendritic spine changes associated with hippocampal long-term synaptic plasticity. Nature 399:66-70.

Fagni L, Bossu JL, Bockaert J (1991) Activation of a large-conductance $\mathrm{Ca}^{2+}$ dependent $\mathrm{K}^{+}$channel by stimulation of glutamate phosphoinositide-coupled receptors in cultured cerebellar granule cells. Eur J Neurosci 3:778-789.

Fagni L, Olivier M, Lafon-Cazal M, Bockaert J (1995) Involvement of divalent ions in the nitric oxide-induced blockade of $N$-methyl-D-aspartate receptors in cerebellar granule cells. Mol Pharmacol 47:1239-1247.

Fiala JC, Feinberg M, Popov V, Harris KM (1998) Synaptogenesis via dendritic filopodia in developing hippocampal area CA1. J Neurosci 18:8900-8911.

Garner CC, Nash J, Huganir RL (2000) PDZ domains in synapse assembly and signalling. Trends Cell Biol 10:274-280.

Goldin M, Segal M, Avignone E (2001) Functional plasticity triggers formation and pruning of dendritic spines in cultured hippocampal networks. J Neurosci 21:186-193.

Halpain S, Hipolito A, Saffer L (1998) Regulation of F-actin stability in dendritic spines by glutamate receptors and calcineurin. J Neurosci 18:9835-9844.

Hering H, Sheng M (2001) Dendritic spines: structure, dynamics and regulation. Nat Rev Neurosci 2:880-888.

Hering H, Sheng M (2003) Activity-dependent redistribution and essential role of cortactin in dendritic spine morphogenesis. J Neurosci 23:11759-11769.

Im YJ, Lee JH, Park SH, Park SJ, Rho S-H, Kang GB, Kim E, Eom SH (2003) Crystal structure of the Shank PDZ-ligand complex reveals a class I PDZ interaction and a novel PDZ-PDZ dimerization. J Biol Chem 278:48099-48104.

Irwin SA, Galvez R, Greenough WT (2000) Dendritic spine structural anomalies in fragile-X mental retardation syndrome. Cereb Cortex 10:1038-1044.

Kim E, Cho K-O, Rothschild A, Sheng M (1996) Heteromultimerization and NMDA receptor-clustering activity of chapsyn-110, a member of the PSD-95 family of proteins. Neuron 17:103-113.

Kim E, Naisbitt S, Hsueh YP, Rao A, Rothschild A, Craig AM, Sheng M (1997) GKAP, a novel synaptic protein that interacts with the guanylate kinase-like domain of the PSD-95/SAP90 family of channel clustering molecules. J Cell Biol 136:669-678.

Korkotian E, Segal M (1999) Release of calcium from stores alters the morphology of dendritic spines in cultured hippocampal neurons. Proc Natl Acad Sci USA 96:12068-12072.

Lim S, Naisbitt S, Yoon J, Hwang JI, Suh PG, Sheng M, Kim E (1999) Characterization of the Shank family of synaptic proteins. Multiple genes, alternative splicing, and differential expression in brain and development. J Biol Chem 274:29510-29518.

Losi G, Prybylowski K, Fu Z, Luo JH, Vicini S (2002) Silent synapses in developing cerebellar granule neurons. J Neurophysiol 87:1263-1270.
Losi G, Prybylowski K, Fu Z, Luo J, Wenthold RJ, Vicini S (2003) PSD-95 regulates NMDA receptors in developing cerebellar granule neurons of the rat. J Physiol (Lond) 548:21-29.

Luscher C, Nicoll RA, Malenka RC, Muller D (2000) Synaptic plasticity and dynamic modulation of the postsynaptic membrane. Nat Neurosci 3:545-550.

Malchiodi-Albedi F, Ceccarini M, Winkelmann JC, Morrow JS, Petrucci TC (1993) The $270 \mathrm{kDa}$ splice variant of erythrocyte beta-spectrin (beta I sigma 2) segregates in vivo and in vitro to specific domains of cerebellar neurons. J Cell Sci 106:67-78.

Matus A (2000) Actin-based plasticity in dendritic spines. Science 290:754-758.

McKinney RA, Capogna M, Durr R, Gahwiler BH, Thompson SM (1999) Miniature synaptic events maintain dendritic spines via AMPA receptor activation. Nat Neurosci 2:44-49.

Medina I, Filippova N, Bakhramov A, Bregestovski P (1996) Calcium-induced inactivation of NMDA receptor-channels evolves independently of rundown in cultured rat brain neurones. J Physiol (Lond) 495:411-427.

Naisbitt S, Kim E, Tu JC, Xiao B, Sala C, Valtschanoff J, Weinberg RJ, Worley PF, Sheng M (1999) Shank, a novel family of postsynaptic density proteins that binds to the NMDA receptor/PSD-95/GKAP complex and cortactin. Neuron 23:569-582.

Park E, Na M, Choi J, Kim S, Lee J-R, Yoon J, Park D, Sheng M, Kim E (2003) The Shank family of postsynaptic density proteins interacts with and promotes synaptic accumulation of the betaPIX guanine nucleotide exchange factor for Racl and Cdc42. J Biol Chem 278:19220-19229.

Passafaro M, Nakagawa T, Sala C, Sheng M (2003) Induction of dendritic spines by an extracellular domain of AMPA receptor subunit GluR2. Nature 424:677-681.

Qualmann B, Boeckers TM, Jeromin M, Gundlfinger ED, Kessels MM (2004) Linkage of the actin cytoskeleton to the postsynaptic density via direct interactions of Abp1 with the ProSAP/Shank family. J Neurosci 24:2481-2495.

Ramackers GJA (2002) Rho proteins, mental retardation and the cellular basis of cognition. Trends Neurosci 25:191-199.

Romorini S, Picoli G, Jiang M, Grossano P, Tonna N, Passafaro M, Zhang M, Sala C (2004) A functional role of postsynaptic density-95-guanylate kinase-associated protein complex in regulating Shank assembly and stability to synapses. J Neurosci 24:9391-9404.

Sala C, Piech V, Wilson NR, Passafaro M, Liu G, Sheng M (2001) Regulation of dendritic spine morphology and synaptic function by Shank and Homer. Neuron 31:115-130.

Sala C, Futai K, Yamamoto K, Worley PF, Hayashi Y, Sheng M (2003) Inhibition of dendritic spine morphogenesis and synaptic transmission by activity-inducible protein Homerla. J Neurosci 23:6327-6337.

Sheng M, Kim E (2000) The Shank family of scaffold proteins. J Cell Sci 113:1851-1856

Tu JC, Xiao B, Naisbitt S, Yuan JP, Petralia RS, Brakeman P, Doan A, Aakalu VK, Lanahan AA, Sheng M, Worley PF (1999) Coupling of mGluR/ Homer and PSD-95 complexes by the Shank family of postsynaptic density proteins. Neuron 23:583-592.

Ursitti JA, Martin L, Resneck WG, Chaney T, Zielke C, Alger BE, Bloch RJ (2001) Spectrins in developing rat hippocampal cells. Brain Res Dev Brain Res 129:81-93.

Wilson HL, Wong ACC, Shaw SR, Tse W-Y, Stapleton GA, Phelan MC, Hu S, Marshall J, McDermid HE (2003) Molecular characterisation of the $22 \mathrm{q} 13$ deletion syndrome supports the role of haploinsufficiency of SHANK3/PROSAP2 in the major neurological symptoms. J Med Genet 40:575-584.

Xiao B, Tu JC, Petralia RS, Yuan JP, Doan A, Breder CD, Ruggiero A, Lanahan AA, Wenthold RJ, Worley PF (1998) Homer regulates the association of group 1 metabotropic glutamate receptors with multivalent complexes of homer-related, synaptic proteins. Neuron 21:707-716.

Yuste R, Bonhoeffer T (2004) Genesis of dendritic spines: insights from ultrastructural and imaging studies. Nat Rev Neurosci 5:24-34. 